Article

\title{
Solid-State Emissive Metallo-Supramolecular Assemblies of Quinoline-Based Acyl Hydrazone
}

\author{
Hye Jin Cho ${ }^{\dagger}$, TaeWoo Kim ${ }^{\dagger}$, Hyunwoo Kim and Changsik Song * (1) \\ Department of Chemistry, Sungkyunkwan University, 2066 Seobu-ro, Jangan-gu, Suwon-si, Gyeonggi-do 16419, \\ Korea; chj9420@skku.edu (H.J.C.); xodntodn@gmail.com (T.K.); khw2651@naver.com (H.K.) \\ * Correspondence: songcs@skku.edu; Tel.: +82-31-299-4567 \\ + These authors contributed equally to this work.
}

Received: 26 December 2019; Accepted: 20 January 2020; Published: 21 January 2020

updates

\begin{abstract}
Development of fluorescence-based sensory materials for metal elements is currently in the mainstream of research due to the simplicity and usability of fluorescence as a method of detection. Herein, we report a novel "bis"-quinoline-based acyl hydrazone-named bQH that could be synthesized by a facile, low-cost method through simple condensation of hydrazide with an aldehyde. This acyl hydrazone showed emissive properties through $\mathrm{Zn}$ selective binding, especially in its solid-state, as shown by experiments such as UV-Vis, photoluminescence (PL), nuclear magnetic resonance (NMR), and inductively-coupled plasma-optical emission spectroscopies (ICP-OES), and energy-dispersive $X$-ray spectroscopy (EDS) mapping. The binding modes in which bQH coordinates to $\mathrm{Zn}^{2+}$ was proved to consist of two modes, 1:1 and 1:2 $\left(\mathrm{bQH}: \mathrm{Zn}^{2+}\right)$, where the binding mode was controlled by the $\mathrm{Zn}^{2+}$ ion content. Under the 1:1 binding mode, bQH- $\mathrm{Zn}^{2+}$ complexes formed a polymeric array through the metallo-supramolecular assembly. The resulting $\mathrm{bQH}-\mathrm{Zn}^{2+}$ complex maintained its fluorescence in solid-state and exhibited excellent fluorescence intensity as compared to the previously reported quinoline-based acyl hydrazone derivative $(\mathrm{mQH})$.
\end{abstract}

Keywords: hydrazone; metallo-supramolecular assembly; solid-state emission

\section{Introduction}

The development of artificial probes to detect metal ions is of great interest because of the tendency of metal ions to act as typical pollutants and essential trace elements in biological systems. The detection of the different species of metal ions by spectroscopic changes-absorption or emission-has been under investigation for the last few decades [1,2]. Based on its simplicity, precise and instantaneous response, and nondestructive properties, chemo-sensors capable of fluorescence detection are becoming more popular compared to conventional analytical methods [3,4].

Zinc is the second most abundant transition metal ion in the human body that plays important metabolic roles, including those in neurological signaling and enzymatic reactions, cell growth, protein and DNA synthesis, and immune function [5,6]. Several artificial receptors for $\mathrm{Zn}$ ion have been developed based on quinoline [7-13], coumarin [14-20], benzoxazole [21-24], BODIPY [25,26], BINOL [27-29], fluorescein [30-32], and rhodamine [33-37] fluorophores.

Hydrazone, a well-known functional group often present in stimuli-responsive materials, is a promising candidate for $\mathrm{Zn}$ ion sensing [38]. Several studies have reported hydrazone-based compounds that can bind metal ions. Various metal ions, including $\mathrm{Al}^{3+}, \mathrm{Cu}^{2+}, \mathrm{Ru}^{2+}, \mathrm{Pd}^{2+}$, and $\mathrm{Pt}^{2+}$, can form a hydrazone-metal complex, and thus, may be applied in photochromic systems [39], molecular motors [40,41], proton transfer systems [42,43], bioactive materials [44-47], etc. Acyl hydrazone derivatives are an especially popular type of hydrazone derivatives for metal ion binding. Among them, hydrazone derivatives with quinoline [48-50], the 3-hydroxy-2-naphthoyl group [51,52], thiophene [53], 
pyrazole [54], or fluorescein [55] have been reported to bind Zn ions and exhibit fluorescence. Although a variety of hydrazone derivatives are known to selectively bind to the $\mathrm{Zn}$ ion, they have seldom been expanded to form a supramolecular assembly $[56,57]$.

Herein, we have designed and synthesized a novel quinoline-based acyl hydrazone, bQH (Figure 1a), that is capable of forming a metallo-supramolecular assembly. It can simply be synthesized by reacting terephthalic dihydrazide with two equivalents of 2-quinolinecarboxaldehyde under ambient conditions. Interestingly, bQH exhibited a bright green emission when its solution was brought into contact with nitrile rubber gloves (Figure 1a, inset). In comparison to previous reports on hydrazone-based $\mathrm{Zn}$ sensing, which dealt with its solution phase, bQH maintained its emission even in solid-state by binding $\mathrm{Zn}^{2+}$ directly on its surface. Further investigations have been employed here to study the emission of $\mathrm{bQH}$, and it has finally been proven that the emission observed on nitrile rubber gloves was due to the selective formation of emissive hydrazone- $\mathrm{Zn}$ ion complex. The selectivity of bQH toward Zn was also confirmed by UV-Vis absorption and emission spectra of bQH solutions with various metal ions. Combined with the relatively weak binding strength of bQH toward $\mathrm{Zn}$ ion, the two binding sites of bQH enabled it to have two binding modes. It was observed that $b Q H$ first formed a polymeric array of the metallo-assembly under the appropriate concentration of $\mathrm{Zn}^{2+}$. Once the $\mathrm{Zn}$ ion fraction increased, the supramolecular polymer, i.e., bQH-Zn complex, disassembled into $\mathrm{bQH}-\mathrm{Zn}_{2}$; this sequence of events was confirmed by a continuous variation method (Job plot) and ${ }^{1} \mathrm{H}-\mathrm{NMR}$ titration.

(a)

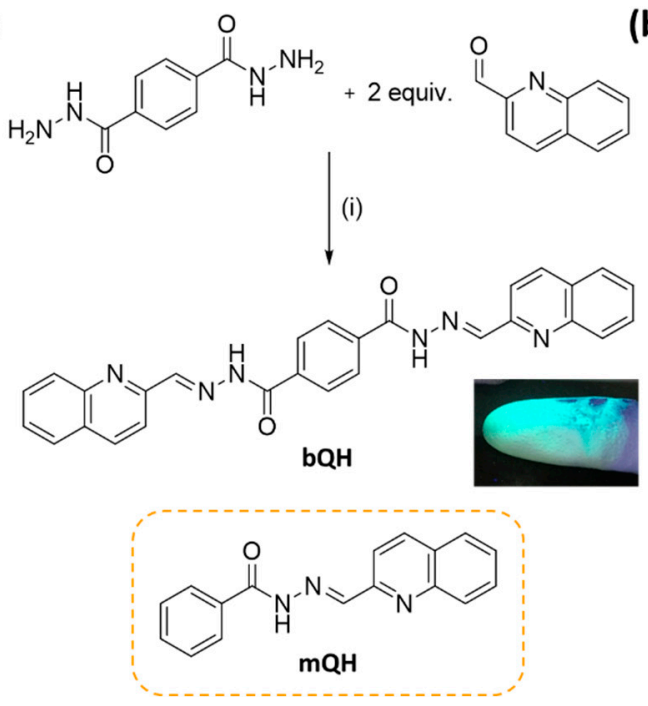

(b)

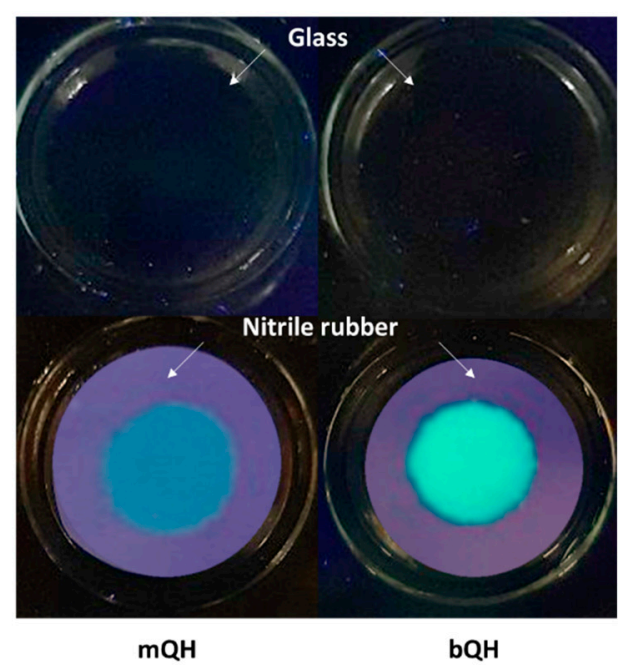

Figure 1. (a) Synthesis of bis-quinoline-based acylhydrazone $(\mathrm{bQH})$ and the structure of mono-quinoline acyl hydrazone $(\mathrm{mQH})$. Reaction conditions: (i) Few drops of $\mathrm{AcOH}, \mathrm{MeOH}, \mathrm{rt}, 8 \mathrm{~h}, 88 \%$. Inset: Emission of bOH on nitrile rubber gloves under $365 \mathrm{~nm}$ ultraviolet (UV) lamp. (b) Images of bQH and mQH $\left(2.5 \times 10^{-4} \mathrm{M}\right.$ in dimethyl sulfoxide (DMSO), $\left.20 \mu \mathrm{L}\right)$ dropcasted on glass (upper) and nitrile rubber (bottom), under $365 \mathrm{~nm}$ UV lamp.

\section{Materials and Methods}

\subsection{General}

All the chemicals were purchased from commercial sources, Sigma-Aldrich (Seoul, Korea), Alfa Aesar (Seoul, Korea), TCI (Tokyo, Japan), Acros Organics (Geel, Belgium), or Samchun Chemical (Seoul, Korea). The chemicals were used as received, without further purification. All reactions were done under an inert atmosphere using standard Schlenk techniques. The nature of synthesized materials was confirmed using nuclear magnetic resonance (NMR) spectroscopy (500 MHz, Bruker); chemical shifts are reported in ppm $(\delta)$ relative to the DMSO- $d_{6}$ solvent residual peak $(\delta 2.50)$ and coupling constants $(J)$ are expressed in Hz. Deuterated solvents were purchased from Cambridge Isotope 
Laboratories (Tweksbury, MA, USA). High-resolution mass spectra (HRMS) were obtained on a JEOL JMS-700 using 3-nitrobenzyl alcohol as a matrix. UV-Vis absorption measurements were obtained on a UV-1800 (Shimadzu) spectrophotometer under ambient conditions (room temperature, air) with a $1.0 \mathrm{~cm}$ quartz cell. Photoluminescence (PL) measurements were performed on a FluoroMate Fs-2 (Scinco). Scanning electron microscope (SEM) image and energy dispersive X-ray spectroscopy (EDS) mapping spectrum were obtained by using FE-SEM JEOL-7100 after vacuum-drying of the piece of nitrile rubber on the grid.

\subsection{Synthesis of (E)-N'-(quinolin-2-ylmethylene)benzohydrazide ( $m Q H)$}

The synthesis of $\mathrm{mQH}$ was carried out as noted in the previous literature [58]. In a flask, 2-quinolinecarboxaldehyde $(0.157 \mathrm{~g}, 1 \mathrm{mmol})$ was added to a suspension of terephthalic dihydrazide $(0.136 \mathrm{~g}, 1 \mathrm{mmol})$ in $25 \mathrm{~mL}$ of ethanol and mixed for $8 \mathrm{~h}$ under room temperature. The reaction mixture was then poured into water and filtered with water under room temperature and dried overnight in a $60{ }^{\circ} \mathrm{C}$ oven. The obtained crude solid was dissolved in dimethylformamide (DMF) under room temperature, which was recrystallized from $\mathrm{H}_{2} \mathrm{O}$ (ratio of DMF: $\mathrm{H}_{2} \mathrm{O}=1: 9$ ) to give the products in 96\% yield (yellowish solid, $0.264 \mathrm{~g}$ ). ${ }^{1} \mathrm{H}$ NMR (500 MHz, DMSO-d $\left.d_{6}\right) \delta 12.21(\mathrm{~s}, 1 \mathrm{H}), 8.63(\mathrm{~s}, 1 \mathrm{H})$, $8.44(\mathrm{~d}, J=8.4 \mathrm{~Hz}, 1 \mathrm{H}), 8.14(\mathrm{~d}, J=8.4 \mathrm{~Hz}, 1 \mathrm{H}), 8.05(\mathrm{~d}, J=8.4 \mathrm{~Hz}, 1 \mathrm{H}), 8.02(\mathrm{~d}, J=8.0 \mathrm{~Hz}, 1 \mathrm{H})$, $7.96(\mathrm{~d}, J=7.2 \mathrm{~Hz}, 2 \mathrm{H}), 7.80(\mathrm{t}, J=7.5 \mathrm{~Hz}, 1 \mathrm{H}), 7.64(\mathrm{t}, J=7.2 \mathrm{~Hz}, 2 \mathrm{H}), 7.57(\mathrm{t}, J=7.4 \mathrm{~Hz}, 2 \mathrm{H}){ }^{13} \mathrm{C}$ NMR $\left.(125 \text { MHz, DMSO-d })_{6}\right) \delta 163.53,153.81,147.96,147.37,136.77,133.20,132.05,130.10,128.91,128.59$, $128.03,127.92,127.78,127.34,117.51$.

\subsection{Synthesis of $\left(N^{\prime} 1 E, N^{\prime} 4 E\right)-N^{\prime} 1, N^{\prime} 4$-bis(isoquinolin-3-ylmethylene)terephthalohydrazide (bQH) [59]}

In a flask, 2-quinolinecarboxaldehyde $(2 \mathrm{mmol})$ was added to a suspension of terephthalic dihydrazide $(1 \mathrm{mmol})$ in $20 \mathrm{~mL}$ of methanol and mixed for $8 \mathrm{~h}$ in the presence of $100 \mu \mathrm{L}$ of glacial acetic acid. The reaction mixture was then poured into water and filtered with water under room temperature and dried overnight in a $60^{\circ} \mathrm{C}$ oven. The crude solid thus obtained was dissolved in DMF under room temperature, which was recrystallized from $\mathrm{H}_{2} \mathrm{O}$ (ratio of DMF: $\mathrm{H}_{2} \mathrm{O}=1: 9$ ) to obtain a product yield of $88 \%$ (yellowish solid, $0.415 \mathrm{~g}$ ). ${ }^{1} \mathrm{H}$ NMR (500 MHz, DMSO- $\left.d_{6}\right) \delta 12.36(\mathrm{~s}, 2 \mathrm{H}), 8.65$ (s, $2 \mathrm{H}), 8.47-8.45(\mathrm{~d}, J=8.6 \mathrm{~Hz}, 2 \mathrm{H}), 8.17-8.15(\mathrm{~d}, J=8.7 \mathrm{~Hz}, 2 \mathrm{H}), 8.13(\mathrm{~s}, 4 \mathrm{H}), 8.08-8.06(\mathrm{~d}, J=8.4 \mathrm{~Hz}$, $2 \mathrm{H}), 8.04-8.03(\mathrm{~d}, J=7.9 \mathrm{~Hz}, 2 \mathrm{H}), 7.83-7.80(\mathrm{t}, J=7.7 \mathrm{~Hz}, 2 \mathrm{H}), 7.67-7.65(\mathrm{t}, J=7.6 \mathrm{~Hz}, 2 \mathrm{H}) .{ }^{13} \mathrm{C}$ NMR $\left(125 \mathrm{MHz}\right.$, DMSO- $\left.d_{6}\right) \delta$ 162.78, 153.70, 148.52, 147.39, 136.84, 136.12, 130.15, 128.95, 128.05, 127.98, $127.42,117.55$. One peak in quinoline seemed to overlap with the peak of core benzene at $128.05 \mathrm{ppm}$. MS (HRMS): $\mathrm{M} / \mathrm{z}$ calculated for $\mathrm{C}_{28} \mathrm{H}_{21} \mathrm{~N}_{6} \mathrm{O}_{2}[\mathrm{M}+\mathrm{H}]^{+}$473.1726; found: 473.1726 .

\subsection{Comparison of $b Q H$ and $m Q H$ on Different Substrates}

A glass slide and a piece of nitrile rubber was prepared, and solutions of $b Q H$ and $m Q H$ $\left(2.5 \times 10^{-4} \mathrm{M}\right)$ were dropped on the surfaces. After drying under vacuum for $12 \mathrm{~h}$, a total of four samples were compared under a 365 nm UV lamp.

\subsection{Metal Screening of $b Q H$}

Stock solution of bQH $\left(5.0 \times 10^{-3} \mathrm{M}\right.$ in DMSO) was added to the stock solutions of metal perchlorates $\left(5.0 \times 10^{-3} \mathrm{M}\right.$ in DMSO) and tetrabutylammonium cyanide (TBA-CN) $\left(5.0 \times 10^{-3} \mathrm{M}\right.$ in DMSO) in a ratio of bQH:metal perchlorate:TBA-CN = 1:4:4. The bQH solution was diluted to a concentration of $5.0 \times 10^{-6} \mathrm{M}$, and added to the same stock solutions of metal perchlorates and TBA-CN in the same ratios to obtain another fluorescence spectra.

\subsection{Absorption and Emission Measurements}

A solution of bQH in DMSO $\left(5.0 \times 10^{-6} \mathrm{M}\right)$ was prepared by diluting the stock solution $\left(5.0 \times 10^{-3} \mathrm{M}\right)$. Zinc solutions with various anions and TBA-CN were prepared as the stock solutions 
$\left(5.0 \times 10^{-3} \mathrm{M}\right)$ and were added to the desired equivalents noted in each figure. The same samples that were used in absorption measurements were used in emission measurements. For the emission spectra obtained from samples of high concentration (absorption $>0.1$ ), a correction for the inner filter effect was performed [60].

\subsection{Inductively Coupled Plasma Optical Emission Spectroscopy (ICP-OES) Measurement}

The bQH solution $\left(6.0 \times 10^{-3} \mathrm{M}\right.$ in DMSO) was dropped on a piece of nitrile rubber and immediately turned into yellow color, so the solution was collected right after it contacted with the nitrile rubber. Concentrations of $\mathrm{Zn}$ (II) in the resulting solution was measured by ICP-OES (Varian) at $213.857 \mathrm{~nm}$.

\subsection{UV-Vis Spectroscopic Titration of $\mathrm{QQH}$ with $\mathrm{Zn}(\mathrm{CN})_{2}$}

The bQH solution $\left(1.0 \times 10^{-5} \mathrm{M}\right.$ in DMSO) was added with the stock solution of $\mathrm{Zn}(\mathrm{CN})_{2}$ in DMSO $\left(2.0 \times 10^{-3} \mathrm{M}\right)$ from 0.0 to 50 equivalents. After having an enough time to form equilibrium states (approximately up to $10 \mathrm{~min}$ ), the absorption and emission spectra were obtained.

\subsection{Fluorescence Quantum Yield (FQY) Measurements}

bQH solutions are the same samples used in UV-Vis spectroscopic titration. The two mQH solutions $\left(1.5 \times 10^{-5} \mathrm{M}\right.$ in DMSO, respectively) were added with the stock solution of $\mathrm{Zn}(\mathrm{CN})_{2}$ in DMSO $\left(2.0 \times 10^{-3} \mathrm{M}\right)$ in two different equivalents of 1.0 and 5.0. After having enough time to form equilibrium states (approximately up to $10 \mathrm{~min}$ ), the absorption and emission spectra were obtained. The relative FQY values were estimated using the absorption and emission spectra as noted in the previous literature [61].

\subsection{0. ${ }^{1} \mathrm{H}-\mathrm{NMR}$ Study on $b \mathrm{QH}-\mathrm{Zn}^{2+}$ Binding Modes}

Solutions of bQH in DMSO- $d_{6}\left(2.0 \times 10^{-2} \mathrm{M}\right)$ were prepared and 2.0 equivalents of tetraethylammonium hydroxide $(\mathrm{TEA}-\mathrm{OH})$ was added, prepared as the stock solution $\left(5.0 \times 10^{-1} \mathrm{M}\right.$ in DMSO- $\left.d_{6}\right)$. Zinc perchlorate, also, was prepared as the stock solution $\left(5.0 \times 10^{-1} \mathrm{M}\right.$ in DMSO- $\left.d_{6}\right)$ and used to the desired equivalents.

\section{Results and Discussion}

As mentioned above, the desired molecule "bis"-quinoline-based acyl hydrazone (bQH) was synthesized from the reaction of terephthalic dihydrazide and 2-quinolinecarboxaldehyde to obtain a good yield (88\%) (Figure 1a). The identity of bQH thus synthesized was confirmed using nuclear magnetic resonance (NMR) spectroscopy and high-resolution mass spectroscopy (HRMS).

Bright green fluorescence of $\mathrm{bQH}$ was first observed when nitrile rubber (acrylonitrile butadiene rubber, NBR) gloves were stained with it. We also employed various substrates including glass, polyacrylonitrile (PAN), latex gloves, Teflon, and nylon filter paper. Among all the other substrates, bQH only emitted fluorescence on the nitrile rubber gloves (Figure S1). To unveil the reason of this solid-state emission, energy dispersive X-ray spectroscopy (EDS) was conducted with NBR gloves (Figure S2). According to the EDS spectrum, various metal cations were dispersed on the surface of the NBR gloves. Hence, we hypothesized that bQH binds with metal ions extracted from the surface of NBR gloves to produce an emissive compound.

Metal binding of quinoline-based acyl hydrazone was reported previously with derivatives of half-structured $(E)-N^{\prime}$-(isoquinolin-3-ylmethylene)benzohydrazide $(\mathrm{mQH})$. To observe the similarities between $\mathrm{mQH}$ and $\mathrm{bQH}$, solutions of each compound were drop-casted on the surface of glass and NBR gloves (Figure 1b). Unlike the bQH, which was emissive on the NBR gloves, $\mathrm{mQH}$ seemed to be less or almost nonemissive on both surfaces. 
Several solutions with metal ions were prepared to determine whether $\mathrm{bQH}$ possessed metal sensing property. In view of the EDS data, $\mathrm{Li}^{+}, \mathrm{Na}^{+}, \mathrm{K}^{+}, \mathrm{Al}^{3+}, \mathrm{Mg}^{2+}, \mathrm{Ag}^{+}, \mathrm{Ca}^{2+}, \mathrm{Fe}^{2+}, \mathrm{Co}^{2+}, \mathrm{Ni}^{2+}, \mathrm{Zn}^{2+}$, $\mathrm{Pb}^{2+}, \mathrm{Cd}^{2+}$, and $\mathrm{Hg}^{2+}$ solutions were prepared (Figure 2a and Figure S3a). The bQH solution with $\mathrm{Zn}^{2+}$ ion showed a bright green fluorescence under UV lamp $(\lambda=365 \mathrm{~nm})$. At first, it seemed that the $\mathrm{Al}^{3+}$ and $\mathrm{Mg}^{2+}$ could also be detected by bQH because they also emitted fluorescence in the presence of bQH in high concentration $\left(5.0 \times 10^{-3} \mathrm{M}\right)$. However, the $\mathrm{Zn}$ specific metal binding property of bQH was confirmed by PL spectra. The metal ion stock solution $\left(5.0 \times 10^{-3} \mathrm{M}\right)$ was added to the solution of $\mathrm{bQH}\left(5.0 \times 10^{-6} \mathrm{M}\right)$ in the amount of two equivalents in DMSO. The PL spectra of metal-combined $\mathrm{bQH}$ solution were measured under the same conditions (Figure S3b). A clear specificity of bQH toward $\mathrm{Zn}^{2+}$ was observed, showing strong emission, while the others were almost nonemissive with the relative PL intensity of $10 \%$ (at $\lambda=500 \mathrm{~nm}$ ). In addition, $\mathrm{bQH}$ bind $\mathrm{Zn} 2+$ selectively in the presence of other competitive metal ions such as $\mathrm{Cd}^{2+}, \mathrm{Ag}^{+}$, or $\mathrm{Li}^{+}$(Figure $\mathrm{S4}$ ). $\mathrm{bQH}$ appeared to bind $\mathrm{Ag}^{+}$or $\mathrm{Li}^{+}$very little, but proved to be able to coordinate to $\mathrm{Cd}^{2+}$ to form the bQH-Cd ${ }^{2+}$ complex, resulting in the absorption change. Interestingly however, the solution of bQH-Cd ${ }^{2+}$ was almost nonemissive. Both $\mathrm{Cd}^{2+}$ and $\mathrm{Zn}^{2+}$ can form the bQH-M ${ }^{2+}$ complex, but bQH seemed to bind $\mathrm{Zn}^{2+}$ more likely than $\mathrm{Cd}^{2+}$. By the successive addition of $\mathrm{Zn}^{2+}$, the solution became emissive, which we attributed to the fact that $\mathrm{Cd}^{2+}$ in bQH-Cd ${ }^{2+}$ was replaced to $\mathrm{Zn}^{2+}$.

(a)

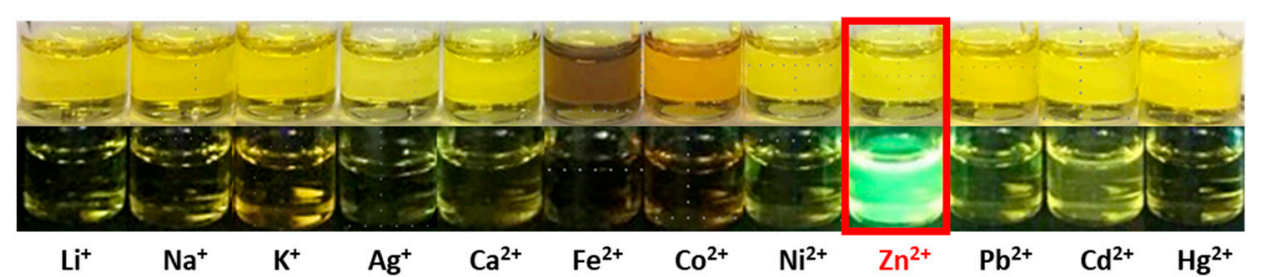

(b)

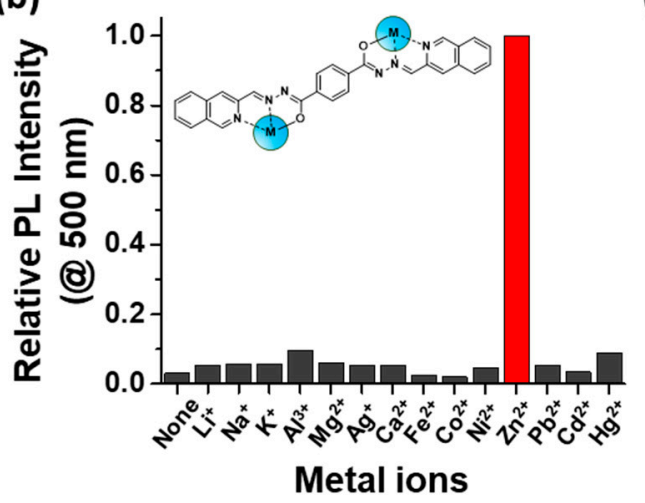

(c)

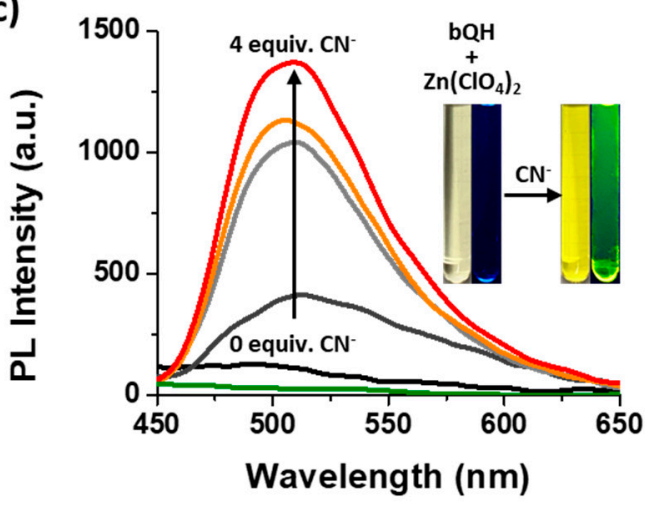

Figure 2. Selective binding of bQH to $\mathrm{Zn}^{2+}$ ion. (a) Images of bQH solutions (5.0 $\times 10^{-3} \mathrm{M}$ in DMSO) mixed with an excess amount of each metal ion (upper). The same samples were placed under a $365 \mathrm{~nm}$ UV lamp (bottom). (b) Comparison of the photoluminescence (PL) intensity of bQH $\left(5.0 \times 10^{-6} \mathrm{M}\right.$ in DMSO) with 2.0 equivalents of metal ions at $\lambda=500 \mathrm{~nm}$, presented relative to the PL intensity of bQH with $\mathrm{Zn}^{2+}$ ion. (c) Increment in PL intensity of bQH $\left(5.0 \times 10^{-6} \mathrm{M}\right)$ with 4.0 equivalents of $\mathrm{Zn}\left(\mathrm{ClO}_{4}\right)_{2}$ by addition of tetrabutylammonium cyanide (TBA-CN) up to 4.0 equivalents in DMSO (measurement conditions: Lamp voltage of $500 \mathrm{~V}, 5 \mathrm{~nm}$ slit width, and $\lambda_{\mathrm{ex}}=350 \mathrm{~nm}$ ). The green line is the emission spectrum of $\mathrm{Zn}\left(\mathrm{ClO}_{4}\right)_{2}\left(2.0 \times 10^{-5} \mathrm{M}\right.$ in DMSO). Inset: Color change (left) and PL increment (right) of bQH solution mixed with $\mathrm{Zn}\left(\mathrm{ClO}_{4}\right)_{2}$ achieved by adding $\mathrm{CN}^{-}$.

Further, we investigated the anion effect on the metal binding capacity of bQH. We proposed that the emission of bQH may be derived from the bQH-metal complex in which complex formation occurs in two steps: (1) Deprotonation followed by (2) metal ion binding. Deprotonation alone cannot make bQH emissive (Figure S5). The emission of the bQH-Zn ${ }^{2+}$ metal complex (Figure 2a,b) could be observed only after the addition of $\mathrm{Zn}^{2+}$ ion accompanied by a change in the absorption spectra 
(Figure S6). The reason behind the nonemissivity bQH and $\mathrm{Zn}^{2+}$ mixture was the nonbasic bulky $\mathrm{ClO}_{4}{ }^{-}$anion. The bQH solution with $\mathrm{Zn}\left(\mathrm{ClO}_{4}\right)_{2}$ started to be emissive immediately with the addition of $\mathrm{CN}^{-}$anion, which is basic enough to deprotonate the acidic proton of bQH (Figure 2c). A further experiment on the anion effect was performed using $\mathrm{Zn}^{2+}$ with various anions- $-\mathrm{CN}^{-}, \mathrm{SO}_{4}{ }^{2-}, \mathrm{Br}^{-}$, $\mathrm{NO}_{3}{ }^{-}, \mathrm{ClO}_{4}{ }^{-}$. The nonbasic anions $\left(\mathrm{Br}^{-}, \mathrm{NO}_{3}{ }^{-}, \mathrm{ClO}_{4}{ }^{-}\right)$did not change the absorption spectra, while the basic anions led to an increasing peak at $420 \mathrm{~nm}$ with increasing PL intensity (Figures S7 and S8). According to the previous literature, the $\mathrm{pK}_{\mathrm{a}}$ of acyl hydrazone $\mathrm{N}-\mathrm{H}$ ranges from 8.8 to 11.3 in aqueous solution [62]. The $\mathrm{pH}$ value of bQH solution $\left(5.0 \times 10^{-6} \mathrm{M}\right.$ in DMSO) was measured to be 8.0 using a $\mathrm{pH}$ meter. Assuming that the $\mathrm{bQH}$ is a weak acid, the $\mathrm{pK}_{\mathrm{a}}$ value of $\mathrm{bQH}$ estimated from the $\mathrm{pH}$ value was 10.7. Therefore, only the anions which have $\mathrm{pK}_{\mathrm{a}}$ of its conjugate acid greater than 10.7 could deprotonate $\mathrm{bQH}$.

Furthermore, $\mathrm{bQH}$ seemed to have a much higher quantum yield as compared to monomeric $\mathrm{mQH}$. The results of the addition of $\mathrm{Zn}(\mathrm{CN})_{2}$ to bQH and $\mathrm{mQH}$ were compared (Figure S9). Upon addition of $\mathrm{Zn}(\mathrm{CN})_{2}$, both $\mathrm{bQH}$ and $\mathrm{mQH}$ showed similar changes in their absorption spectra, a decrease in peak intensity at $320 \mathrm{~nm}$ and an increase at $420 \mathrm{~nm}$. However, the bQH with four equivalents of $\mathrm{Zn}(\mathrm{CN})_{2}$ exhibited more intense fluorescence than the $\mathrm{mQH}$, with the intensity being almost 10 times higher. This is a remarkable increment in PL intensity which could be explained only by the higher quantum yield of $\mathrm{bQH}$, even if we considered that $\mathrm{bQH}$ had double the amount of fluorophores as compared to $\mathrm{mQH}$.

The $\mathrm{Zn}^{2+}$ ion sensing ability of bQH was once again confirmed by inductively coupled plasma-optical emission spectroscopy (ICP-OES) (Figure S10). The stock solution of bQH $\left(6.0 \times 10^{-3} \mathrm{M}\right)$ was dropped on a piece of NBR gloves, and the concentration of $\mathrm{Zn}^{2+}$ ion contained in the bQH solution was measured. According to the resulting data, approximately $20.3 \mathrm{ppm}$ of $\mathrm{Zn}^{2+}$ was extracted from the surface of the NBR gloves.

Further in-depth investigation of the binding mechanism of bQH toward $\mathrm{Zn}^{2+}$ ion was performed using a continuous variation method (Job plot). Before the Job's analysis, an unexpected change in UV-Vis absorption spectra was observed (Figure 3a and Figure S11a). During the measurement, we increased the mole fraction of $\mathrm{Zn}^{2+}\left(\chi_{\mathrm{Zn}}\right)$; the peak at $420 \mathrm{~nm}$ arose as observed before because of the formation of the $b Q H-\mathrm{Zn}^{2+}$ complex from $b Q H$ after deprotonation. A decrease in the corresponding absorption band was observed when $\chi_{\mathrm{Zn}}>0.5$ and simultaneously, red shifting of the absorption band began, which indicated that at least two different species participated in the $\mathrm{Zn}^{2+}$ binding of bQH.

Considering the above, Job's analysis was conducted with the PL spectra (Figure S11b). The PL intensity increased initially and then decreased after a certain point, which was the same as the UV-Vis absorption spectra (Figure 3b). The resulting Job plot exhibited a deviation from the normal triangular shape into hyperboles. Hyperbole-shaped Job plots usually appear when the binding constants are relatively small. In this case, the hyperbole-shaped plot could indicate the existence of $\mathrm{HnGm}(\mathrm{H}$ : Host and G: Guest molecule; in our system, $\mathrm{H}: \mathrm{bQH}$ and G: $\mathrm{Zn}^{2+}$ ) as well in several stoichiometries. The emission maximum was observed at $\chi_{\mathrm{Zn}} \approx 0.55 \sim 0.75$, suggesting that both $1: 1$ and $1: 2$ binding modes could be present.

We also analyzed the binding modes of bQH toward $\mathrm{Zn}^{2+}$, using a UV-Vis spectroscopic titration (Figure $3 \mathrm{c}$ and Figure S12). Two wavelengths of 420 and $430 \mathrm{~nm}$ were selected to perform nonlinear regression analysis, which are the absorption maximum wavelengths of $\mathrm{bQH}-\mathrm{Zn}$ and $\mathrm{bQH}-\mathrm{Zn}_{2}$, respectively. Using the fitting program for 1:1 and 1:2 binding mode [63], we could obtain more reliable stepwise (thermodynamic) binding constants $K_{1}$ and $K_{2}$ from 1:2 binding mode (see Supplementary Materials, Table S2). The quality of fitting results was compared with calculated " $\operatorname{cov}_{\text {fit }}$ " values. The covariance of the fit, " $\operatorname{cov}_{\text {fit }}$ ", is a parameter which represents how the data fits well to the given plot. The lower the value, the better the model explains datasets. The $K_{1}$ was estimated to be $5.02 \times 10^{6} \mathrm{M}^{-1}$ while the $K_{2}$ was $8.14 \times 10^{5} \mathrm{M}^{-1}$, which are in the range of previously reported $K$ values of similar chelators from $1.00 \times 10^{4.75}$ to $1.00 \times 10^{9.6}[48,49,59]$. The fitting results indicated negative cooperativity $\left(\alpha=4 K_{2} / K_{1}<1\right)$, meaning that bQH favors 1:1 binding (i.e., supramolecular 
assembly) than 1:2 binding by addition of $\mathrm{Zn}(\mathrm{CN})_{2}$. In addition, the limit of detection (LOD) and limit of quantitation (LOQ) values of bQH toward $\mathrm{Zn}(\mathrm{CN})_{2}$ were estimated to be 73.8 and $246 \mathrm{nM}$, respectively (Figure S12d). The detection limit of precedent $N$-acylhydrazone-based Zn sensors ranged from few to few tenths of $\mathrm{nM}[53,64-66]$, thus our result seems to be a reasonable value. It should be noted that bQH appears to work well for $\mathrm{Zn}^{2+}$ sensing in the solid state.
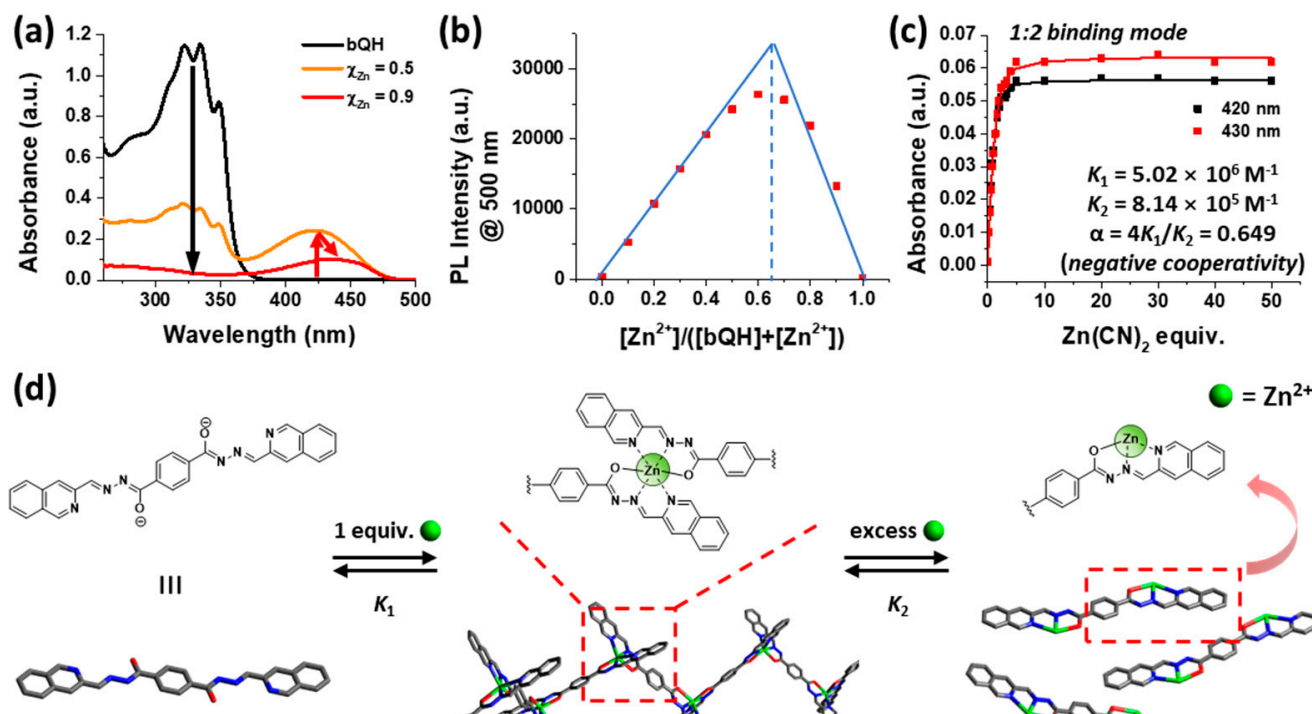

Deprotonated bQH
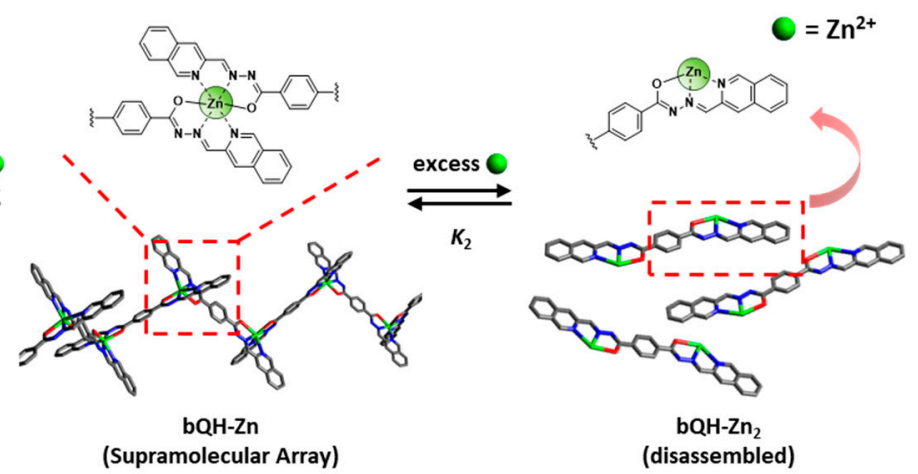

Figure 3. Study of the binding mechanism with ultraviolet-visible (UV-Vis) and PL spectroscopy. (a) The absorption spectra of a solution of bQH $\left(1.0 \times 10^{-5} \mathrm{M}\right.$ in DMSO) with increasing ratio of $\mathrm{Zn}^{2+}$ ion performed for the Job's plot of bQH- $\mathrm{Zn}^{2+}\left([\mathrm{bQH}]+\left[\mathrm{Zn}^{2+}\right]=2.0 \times 10^{-5} \mathrm{M}\right)$. (b) Corresponding Job's analysis of bQH- $\mathrm{Zn}^{2+}$ with PL data. (c) The nonlinear regression analysis of absorption titration at 420 (black) and $430 \mathrm{~nm}$ (red) with the binding mode 1:2. (d) Schematic representation of the binding mechanism of $\mathrm{bQH}-\mathrm{Zn}^{2+}$. The coordination occupied by any solvent molecules or ligands have been omitted for clarity.

It has been known that two molecules of a quinoline-acyl hydrazone ligand can form an octahedral-type bond to $\mathrm{Zn}^{2+}$. For bQH, two quinoline moieties were connected with a rigid benzene ring, which made it impossible to allow intra-molecular binding of the two quinolines to the same $\mathrm{Zn}^{2+}$ ion. Thus, we hypothesized that upon addition of one equivalent of $\mathrm{Zn}^{2+}$ per $\mathrm{bQH}$ (i.e., two parts of quinoline moiety), inter-molecular binding of two quinoline moieties would form supramolecular polymers (metallo-supramolecular assembly). Further addition of $\mathrm{Zn}^{2+}$ would disassemble the metallo-supramolecular polymers into bQH- $\mathrm{Zn}_{2}$ complexes with extra coordination of solvent molecules (Figure 3d). Interestingly, supramolecular polymeric bQH-Zn and monomeric $\mathrm{bQH}-\mathrm{Zn}_{2}$ complexes seemed to be emissive, even in the solid states.

The fluorescence quantum yield (FQY) measurements were performed to compare the emission properties of $\mathrm{bQH}-\mathrm{Zn}^{2+}$ complexes precisely. From the emission spectra obtained during the UV-Vis spectroscopic titration, FQY values of $b Q H-Z n$ and bQH- $\mathrm{Zn}_{2}$ were estimated and those for $\mathrm{Zn}^{2+}$ bound complexes of $\mathrm{mQH}$ were also measured (see Supplementary Materials, Table S3) [61]. Since isolating the pure compounds was difficult, each complex were prepared by mixing the solutions of QH with two different $\mathrm{Zn}(\mathrm{CN})_{2}$ equivalents of 1.0 and 5.0. We assumed the desired form of complexes would be the major compound in the solutions. Although all the obtained FQY values were very low $(\sim 1.00 \%)$, a significant increase in emission of $\mathrm{bQH}$ upon binding to $\mathrm{Zn}^{2+}$ enabled its detection. In addition, we observed an increase 2-3 folds in FQY values of bQH- $\mathrm{Zn}^{2+}$ complexes compared to mQH- $\mathrm{Zn}^{2+}$. 
The existence of supramolecular polymeric bQH-Zn and monomeric bQH- $\mathrm{Zn}_{2}$ complexes was also proved by the ${ }^{1} \mathrm{H}-\mathrm{NMR}$ study (Figure 4 and Figure S13). We first mixed the bQH solution $\left(2.0 \times 10^{-2} \mathrm{M}\right.$ in DMSO$)$ with 2.0 equivalent of tetraethylammonium hydroxide. The imino proton at $12.37 \mathrm{ppm}$ in the original ${ }^{1} \mathrm{H}$ NMR spectrum of bQH disappeared while the protons in core benzene ring and quinoline rings exhibited relative upshifts, indicating the deprotonation of bQH. By adding the $\mathrm{Zn}\left(\mathrm{ClO}_{4}\right)_{2}$ gradually, a clear shifting of the protons were observed. When the $\mathrm{Zn}^{2+}$ was added in 1.0 equivalent, the bQH started to bind the $\mathrm{Zn}^{2+}$. The 1:1 stoichiometry leads the formation of polymeric $\mathrm{bQH}-\mathrm{Zn}$ and it starts to precipitate in the solution (seen in the inset of Figure $4 \mathrm{~b}$ ), that is insoluble in common polar solvents including DMSO, DMF, methanol, chloroform, and water. The precipitate broadens the ${ }^{1} \mathrm{H}-\mathrm{NMR}$ spectrum, thus making it difficult to assign each proton accurately. Despite the difficulties in interpreting the peaks in the ${ }^{1} \mathrm{H}-\mathrm{NMR}$ spectrum, a clear shift of $\mathrm{H}^{4}$ and $\mathrm{H}^{\mathrm{b}}$ to the downfield was observed, which could be assigned to the coordination of bQH to $\mathrm{Zn}^{2+}$ ion $[58,59]$. Upon further addition of $\mathrm{Zn}^{2+}$ to 2.0 equivalents, $\mathrm{H}^{4}$ and $\mathrm{H}^{\mathrm{b}}$ exhibited further shifting to upfield, and the solution started to become clear again. The increment in $\mathrm{Zn}^{2+}$ content up to 4.0 equivalents, however, did not lead to any significant changes in chemical shifts of protons, but the sharpening of the spectrum was observed. This stationary and sharpened peaks in the ${ }^{1} \mathrm{H}-\mathrm{NMR}$ spectrum indicates that the formation of monomeric bQH- $\mathrm{Zn}_{2}$ complexes is predominant, which comes from the bQH- $\mathrm{Zn}$ after it disassembles by excess amount of $\mathrm{Zn}^{2+}$.
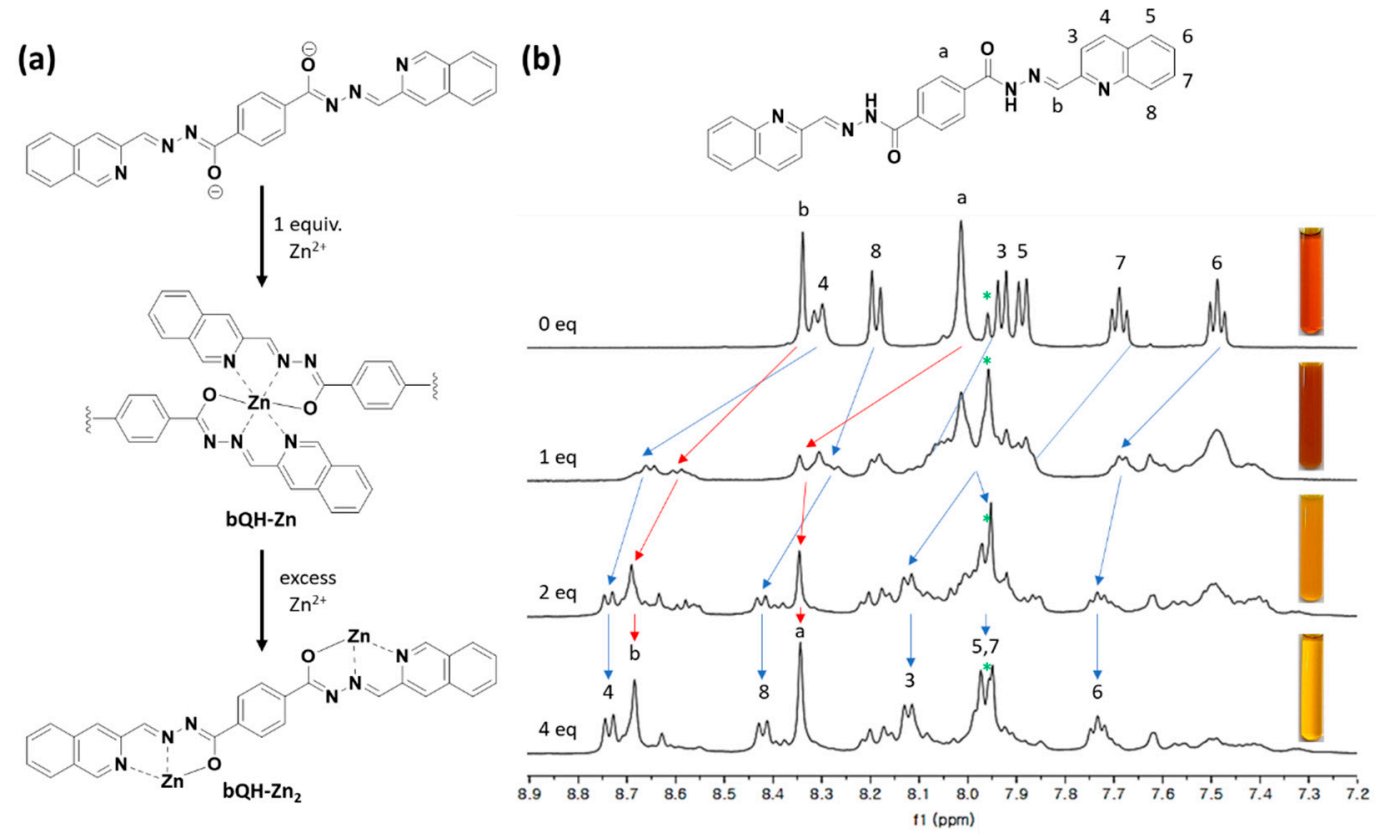

Figure 4. (a) Schematic representation of changes in deprotonated bQH followed by addition of the $\mathrm{Zn}^{2+}$ ion. (b) Partial ${ }^{1} \mathrm{H}-\mathrm{NMR}(500 \mathrm{MHz})$ of bQH $\left(2.0 \times 10^{-2} \mathrm{M}\right)$ in DMSO- $d_{6}$ with 2 equivalents of tetraethylammonium hydroxide, by adding up to 4 equivalents of $\mathrm{Zn}\left(\mathrm{ClO}_{4}\right)_{2}$. The * (in green) indicates the solvent peak.

\section{Conclusions}

In summary, a bis-quinoline-based acyl hydrazone fluorescent probe $(\mathrm{bQH})$ was designed and synthesized. Hydrazone has the advantage of enabling the facile synthesis of desired molecules at a low cost. The emissive nature of bQH was first observed on the surface of NBR gloves. For an in-depth understanding of $\mathrm{bQH}$ and its emissive nature, various experiments such as UV-Vis absorption, PL, NMR, ICP-OES spectroscopies, and EDS mapping were performed. It was discovered that bQH binds to $\mathrm{Zn}^{2+}$ ion selectively, making a bQH- $\mathrm{Zn}^{2+}$ complex that is emissive even in the solid-state. By addition of $\mathrm{Zn}^{2+}$ to $\mathrm{bQH}$, the planarization of bQH led an increasing absorption band at 420 $\mathrm{nm}$. The planarization further restricted the rotation of $\mathrm{C}-\mathrm{C}$ bond between phenyl ring and acyl 
moiety, making the bQH- $\mathrm{Zn}^{2+}$ complex emissive. The binding modes of the bQH- $\mathrm{Zn}^{2+}$ complex were discovered to be composed of two parts with $\mathrm{bQH}: \mathrm{Zn}^{2+}$ ratios of 1:1 and 1:2. The relatively weak binding strength of $\mathrm{bQH}$, combined with the two binding sites, enables bQH to bind $\mathrm{Zn}^{2+}$ in two ways: Through metallo-suparmolecular polymers and monomeric complexes. These findings would encourage further development of fluorescent metal probes and their application in the research on solid-state emission.

Supplementary Materials: The Supplementary Materials are available online at http://www.mdpi.com/1424-8220/ 20/3/600/s1.

Author Contributions: C.S., H.J.C., and T.K. conceived and designed the experiments; T.K. and H.K. performed the experiments; H.J.C. and C.S. wrote the paper; C.S. supervised the research. All authors have read and agreed to the published version of the manuscript.

Acknowledgments: This research was supported by the Nano Material Development Program (2012M3A7B4049644) and the Basic Science Research Program (2019R1A2C1004256) through the National Research Foundation of Korea (NRF) funded by the Ministry of Science and ICT, Republic of Korea.

Conflicts of Interest: The authors declare no conflict of interest.

\section{References}

1. Keefe, M.H.; Benkstein, K.D.; Hupp, J.T. Luminescent sensor molecules based on coordinated metals: A review of recent developments. Coord. Chem. Rev. 2000, 205, 201-228. [CrossRef]

2. Kaur, B.; Kaur, N.; Kumar, S. Colorimetric metal ion sensors-A comprehensive review of the years 2011-2016. Coord. Chem. Rev. 2018, 358, 13-69. [CrossRef]

3. Schaferling, M. The Art of Fluorescence Imaging with Chemical Sensors. Angew. Chem. Int. Ed. 2012, 51, 3532-3554. [CrossRef]

4. Vendrell, M.; Zhai, D.T.; Er, J.C.; Chang, Y.T. Combinatorial Strategies in Fluorescent Probe Development. Chem. Rev. 2012, 112, 4391-4420. [CrossRef]

5. Berg, J.M.; Shi, Y.G. The galvanization of biology: A growing appreciation for the roles of zinc. Science 1996, 271, 1081-1085. [CrossRef]

6. Wu, Z.K.; Chen, Q.Q.; Yang, G.Q.; Mao, C.B.; Liu, J.A.; Yang, S.Y.; Ma, J.S. Novel fluorescent sensor for Zn(II) based on bis(pyrrol-2-yl-methyleneamine) ligands. Sens. Actuators B 2004, 99, 511-515. [CrossRef]

7. Fahrni, C.J.; O'Halloran, T.V. Aqueous coordination chemistry of quinoline-based fluorescence probes for the biological chemistry of zinc. J. Am. Chem. Soc. 1999, 121, 11448-11458. [CrossRef]

8. Zhou, X.Y.; Yu, B.R.; Guo, Y.L.; Tang, X.L.; Zhang, H.H.; Liu, W.S. Both Visual and Fluorescent Sensor for $\mathrm{Zn}^{2+}$ Based on Quinoline Platform. Inorg. Chem. 2010, 49, 4002-4007. [CrossRef] [PubMed]

9. Zhou, X.Y.; Li, P.X.; Shi, Z.H.; Tang, X.L.; Chen, C.Y.; Liu, W.S. A Highly Selective Fluorescent Sensor for Distinguishing Cadmium from Zinc Ions Based on a Quinoline Platform. Inorg. Chem. 2012, 51, 9226-9231. [CrossRef] [PubMed]

10. Mao, Z.Q.; Hu, L.; Dong, X.H.; Zhong, C.; Liu, B.F.; Liu, Z.H. Highly Sensitive Quinoline-Based Two-Photon Fluorescent Probe for Monitoring Intracellular Free Zinc Ions. Anal. Chem. 2014, 86, 6548-6554. [CrossRef] [PubMed]

11. Song, H.H.; Zhang, Z. A quinoline-based ratiometric fluorescent probe for discriminative detection of $\mathrm{Zn}^{2+}$ and $\mathrm{Cd}^{2+}$ with different binding modes, and its $\mathrm{Zn}^{2+}$ complex for relay sensing of pyrophosphate and adenosine triphosphate. Dyes Pigment. 2019, 165, 172-181. [CrossRef]

12. Fu, H.R.; Liu, H.Y.; Zhao, L.; Xiao, B.R.; Fan, T.T.; Jiang, Y.Y. A quinoline-based selective 'turn on' chemosensor for zinc(II) via quad-core complex, and its application in live cell imaging. Tetrahedron 2019, 75, 130710. [CrossRef]

13. Yun, D.; Chae, J.; So, H.; Lee, H.; Kim, K.; Kim, C. Sensing of zinc ion and sulfide by a highly practical and water-soluble fluorescence sensor: Applications in test kits and zebrafish. New J. Chem. 2020, 44, 442-449. [CrossRef]

14. Wu, J.S.; Liu, W.M.; Zhuang, X.Q.; Wang, F.; Wang, P.F.; Tao, S.L.; Zhang, X.H.; Wu, S.K.; Lee, S.T. Fluorescence turn on of coumarin derivatives by metal cations: A new signaling mechanism based on $\mathrm{C}=\mathrm{N}$ isomerization. Org. Lett. 2007, 9, 33-36. [CrossRef] [PubMed] 
15. Komatsu, K.; Urano, Y.; Kojima, H.; Nagano, T. Development of an iminocoumarin-based zinc sensor suitable for ratiometric fluorescence imaging of neuronal zinc. J. Am. Chem. Soc. 2007, 129, 13447-13454. [CrossRef]

16. Mizukami, S.; Okada, S.; Kimura, S.; Kikuchi, K. Design and Synthesis of Coumarin-Based $\mathrm{Zn}^{2+}$ Probes for Ratiometric Fluorescence Imaging. Inorg. Chem. 2009, 48, 7630-7638. [CrossRef]

17. Cao, D.X.; Liu, Z.Q.; Verwilst, P.; Koo, S.; Jangjili, P.; Kim, J.S.; Lin, W.Y. Coumarin-Based Small-Molecule Fluorescent Chemosensors. Chem. Rev. 2019, 119, 10403-10519. [CrossRef]

18. Dey, S.; Maity, S.; Pal, K.; Jana, K.; Sinha, C. Oxidative dehydrogenation of a coumarinyl scaffold with Copper ion and metal ion detection in human liver cancer cell (HepG2). Dalton Trans. 2019, 48, 17818-17830. [CrossRef]

19. Yanfang, S.; Hualai, W.; Hui, B. A coumarin-based turn-on chemosensor for selective detection of $\mathrm{Zn}$ (II) and application in live cell imaging. Spectrochim. Acta Part A Mol. Biomol. Spectrosc. 2019, 117746. [CrossRef]

20. Fu, J.; Yao, K.; Li, B.; Mei, H.; Chang, Y.; Xu, K. Coumarin-based colorimetric-fluorescent sensors for the sequential detection of $\mathrm{Zn}^{2+}$ ion and phosphate anions and applications in cell imaging. Spectrochim. Acta Part A Mol. Biomol. Spectrosc. 2019, 117790. [CrossRef]

21. Taki, M.; Wolford, J.L.; O'Halloran, T.V. Emission ratiometric imaging of intracellular zinc: Design of a benzoxazole fluorescent sensor and its application in two-photon microscopy. J. Am. Chem. Soc. 2004, 126, 712-713. [CrossRef] [PubMed]

22. Chen, W.H.; Xing, Y.; Pang, Y. A Highly Selective Pyrophosphate Sensor Based on ESIPT Turn-On in Water. Org. Lett. 2011, 13, 1362-1365. [CrossRef] [PubMed]

23. Kwon, J.E.; Lee, S.; You, Y.; Baek, K.H.; Ohkubo, K.; Cho, J.; Fukuzumi, S.; Shin, I.; Park, S.Y.; Nam, W. Fluorescent Zinc Sensor with Minimized Proton-Induced Interferences: Photophysical Mechanism for Fluorescence Turn-On Response and Detection of Endogenous Free Zinc Ions. Inorg. Chem. 2012, 51, 8760-8774. [CrossRef] [PubMed]

24. Asaithambi, G.; Periasamy, V.; Karuppannan, N. Fluorescence sensing response of zinc (II) and pyrophosphate ions by benzoxazole appended dipodal Schiff base. J. Photochem. Photobiol. A Chem. 2019, 370, 75-83. [CrossRef]

25. He, H.; $\mathrm{Ng}$, D.K.P. Differential Detection of $\mathrm{Zn}^{2+}$ and $\mathrm{Cd}^{2+}$ Ions by BODIPY-Based Fluorescent Sensors. Chem. Asian J. 2013, 8, 1441-1446. [CrossRef] [PubMed]

26. Ojida, A.; Sakamoto, T.; Inoue, M.; Fujishima, S.; Lippens, G.; Hamachi, I. Fluorescent BODIPY-Based Zn(II) Complex as a Molecular Probe for Selective Detection of Neurofibrillary Tangles in the Brains of Alzheimer's Disease Patients. J. Am. Chem. Soc. 2009, 131, 6543-6548. [CrossRef]

27. Hou, J.L.; Song, F.Y.; Wang, L.; Wei, G.; Cheng, Y.X.; Zhu, C.J. In Situ Generated 1:1 Zn(II)-Containing Polymer Complex Sensor for Highly Enantioselective Recognition of N-Boc-Protected Alanine. Macromolecules 2012, 45, 7835-7842. [CrossRef]

28. $\mathrm{Pu}, \mathrm{L}$. Simultaneous Determination of Concentration and Enantiomeric Composition in Fluorescent Sensing. Acc. Chem. Res. 2017, 50, 1032-1040. [CrossRef]

29. Iqbal, S.; Yu, S.S.; Zhao, F.; Wang, Y.C.; Tian, J.; Jiang, L.; Du, Y.; Yu, X.Q.; Pu, L. Discriminating three biothiols by using one fluorescent probe. Tetrahedron Lett. 2018, 59, 3397-3400. [CrossRef]

30. Nolan, E.M.; Jaworski, J.; Okamoto, K.I.; Hayashi, Y.; Sheng, M.; Lippard, S.J. QZ1 and QZ2: Rapid, reversible quinoline-derivatized fluoresceins for sensing biological Zn(II). J. Am. Chem. Soc. 2005, 127, 16812-16823. [CrossRef]

31. Zhao, G.; Wei, G.; Yan, Z.; Guo, B.; Guang, S.; Wu, R.; Xu, H. A multiple fluorescein-based turn-on fluorophore (FHCS) identified for simultaneous determination and living imaging of toxic $\mathrm{Al}^{3+}$ and $\mathrm{Zn}^{2+}$ by improved Stokes shift. Anal. Chim. Acta 2019, 1095, 185-196. [CrossRef] [PubMed]

32. Das, B.; Jana, A.; Das Mahapatra, A.; Chattopadhyay, D.; Dhara, A.; Mabhai, S.; Dey, S. Fluorescein derived Schiff base as fluorimetric zinc (II) sensor via 'turn on' response and its application in live cell imaging. Spectrochim. Acta Part A Mol. Biomol. Spectrosc. 2019, 212, 222-231. [CrossRef] [PubMed]

33. Han, Z.X.; Zhang, X.B.; Zhuo, L.; Gong, Y.J.; Wu, X.Y.; Zhen, J.; He, C.M.; Jian, L.X.; Jing, Z.; Shen, G.L.; et al. Efficient Fluorescence Resonance Energy Transfer-Based Ratiometric Fluorescent Cellular Imaging Probe for $\mathrm{Zn}^{2+}$ Using a Rhodamine Spirolactam as a Trigger. Anal. Chem. 2010, 82, 3108-3113. [CrossRef]

34. Du, P.W.; Lippard, S.J. A Highly Selective Turn-On Colorimetric, Red Fluorescent Sensor for Detecting Mobile Zinc in Living Cells. Inorg. Chem. 2010, 49, 10753-10755. [CrossRef] [PubMed] 
35. Tomat, E.; Lippard, S.J. Ratiometric and Intensity-Based Zinc Sensors Built on Rhodol and Rhodamine Platforms. Inorg. Chem. 2010, 49, 9113-9115. [CrossRef] [PubMed]

36. Pang, B.J.; Li, C.R.; Yang, Z.Y. A novel chromone and rhodamine derivative as fluorescent probe for the detection of $\mathrm{Zn}(\mathrm{II})$ and $\mathrm{Al}(\mathrm{III})$ based on two different mechanisms. Spectrochim. Acta Part A Mol. Biomol. Spectrosc. 2018, 204, 641-647. [CrossRef]

37. Xue, J.; Tian, L.M.; Yang, Z.Y. A novel rhodamine-chromone Schiff-base as turn-on fluorescent probe for the detection of $\mathrm{Zn}(\mathrm{II})$ and Fe(III) in different solutions. J. Photochem. Photobiol. A Chem. 2019, 369, 77-84. [CrossRef]

38. Tatum, L.A.; Su, X.; Aprahamian, I. Simple Hydrazone Building Blocks for Complicated Functional Materials. Acc. Chem. Res. 2014, 47, 2141-2149. [CrossRef]

39. Li, K.; Xiang, Y.; Wang, X.Y.; Li, J.; Hu, R.R.; Tong, A.J.; Tang, B.Z. Reversible Photochromic System Based on Rhodamine B Salicylaldehyde Hydrazone Metal Complex. J. Am. Chem. Soc. 2014, 136, 1643-1649. [CrossRef]

40. Su, X.; Aprahamian, I. Zinc(II)-Regulation of Hydrazone Switch Isomerization Kinetics. Org. Lett. 2013, 15, 5952-5955. [CrossRef]

41. Stadler, A.M.; Lehn, J.M.P. Coupled Nanomechanical Motions: Metal-Ion-Effected, pH-Modulated, Simultaneous Extension/Contraction Motions of Double-Domain Helical/Linear Molecular Strands. J. Am. Chem. Soc. 2014, 136, 3400-3409. [CrossRef] [PubMed]

42. Kobayashi, A.; Dosen, M.; Chang, M.; Nakajima, K.; Noro, S.; Kato, M. Synthesis of Metal-Hydrazone Complexes and Vapochromic Behavior of Their Hydrogen-Bonded Proton-Transfer Assemblies. J. Am. Chem. Soc. 2010, 132, 15286-15298. [CrossRef] [PubMed]

43. Nakanishi, T.; Hori, Y.; Sato, H.; Wu, S.Q.; Okazawa, A.; Kojima, N.; Yamamoto, T.; Einaga, Y.; Hayami, S.; Horie, Y.; et al. Observation of Proton Transfer Coupled Spin Transition and Trapping of Photoinduced Metastable Proton Transfer State in an Fe(II) Complex. J. Am. Chem. Soc. 2019, 141, 14384-14393. [CrossRef] [PubMed]

44. Li, Y.Q.; Yang, Z.W.; Zhou, M.Y.; Li, Y.; He, J.; Wang, X.H.; Lin, Z.F. Ni(II) and Co(II) complexes of an asymmetrical aroylhydrazone: Synthesis, molecular structures, DNA binding, protein interaction, radical scavenging and cytotoxic activity. RSC Adv. 2017, 7, 41527-41539. [CrossRef]

45. Li, Y.Q.; Yang, Z.W.; Zhou, M.Y.; Li, Y. Synthesis and crystal structure of new monometallic Ni(II) and Co(II) complexes with an asymmetrical aroylhydrazone: Effects of the complexes on DNA/protein binding property, molecular docking, and in vitro anticancer activity. RSC Adv. 2017, 7, 49404-49422. [CrossRef]

46. Xie, L.Y.; Zhang, Y.; Xu, H.; Gong, C.D.; Du, X.L.; Li, Y.; Wang, M.; Qin, J. Synthesis, structure and bioactivity of $\mathrm{Ni}^{2+}$ and $\mathrm{Cu}^{2+}$ acylhydrazone complexes. Acta Cryst. C 2019, 75, 927-934. [CrossRef]

47. Neethu, K.S.; Eswaran, J.; Theetharappan, M.; Nattamai, S.P.B.; Neelakantan, M.; Velusamy, K.M. Organoruthenium (II) complexes featuring pyrazole-linked Schiff base ligands: Crystal structure, DNA/BSA interactions, cytotoxicity and molecular docking. Appl. Organometal. Chem. 2019, 33, 1-16. [CrossRef]

48. Ray, D.; Foy, J.T.; Hughes, R.P.; Aprahamian, I. A switching cascade of hydrazone-based rotary switches through coordination-coupled proton relays. Nat. Chem. 2012, 4, 757-762. [CrossRef]

49. Pramanik, S.; Aprahamian, I. Hydrazone Switch-Based Negative Feedback Loop. J. Am. Chem. Soc. 2016, 138, 15142-15145. [CrossRef]

50. Wu, W.N.; Mao, P.D.; Wang, Y.; Zhao, X.L.; Xu, Z.Q.; Xu, Z.H.; Xue, Y. Quinoline containing acetyl hydrazone: An easily accessible switch-on optical chemosensor for $\mathrm{Zn}^{2+}$. Spectrochim. Acta Part A Mol. Biomol. Spectrosc. 2018, 188, 324-331. [CrossRef]

51. Yan, J.; Fan, L.; Qin, J.C.; Li, C.R.; Yang, Z.Y. A novel and resumable Schiff-base fluorescent chemosensor for Zn(II). Tetrahedron Lett. 2016, 57, 2910-2914. [CrossRef]

52. Ribeiro, N.; Galvão, A.M.; Gomes, C.S.; Ramos, H.; Pinheiro, R.; Saraiva, L.; Ntungwe, E.; Isca, V.; Rijo, P.; Cavaco, I. Naphthoylhydrazones: Coordination to metal ions and biological screening. New J. Chem. 2019, 43, 17801-17818. [CrossRef]

53. Suganya, S.; Velmathi, S.; Venkatesan, P.; Wu, S.P.; Boobalan, M.S. A highly fluorescent zinc complex of a dipodal $\mathrm{N}$-acyl hydrazone as a selective sensor for $\mathrm{H}_{2} \mathrm{PO}_{4}{ }^{-}$ions and application in living cells. Inorg. Chem. Front. 2015, 2, 649-656. [CrossRef] 
54. Zhang, H.h.; Dou, W.; Liu, W.s.; Tang, X.1.; Qin, W.w. A 2-Pyrazoline-Functionalized Zinc Complex: Available N-AgI Interaction Modulating Its Fluorescence Properties. Eur. J. Inorg. Chem. 2011, 2011, 748-753. [CrossRef]

55. Villada, J.D.; D’Vries, R.F.; Macias, M.; Zuluaga, F.; Chaur, M.N. Structural characterization of a fluorescein hydrazone molecular switch with application towards logic gates. New J. Chem. 2018, 42, 18050-18058. [CrossRef]

56. Chow, C.F.; Fujii, S.; Lehn, J.M. Metallodynamers: Neutral dynamic metallosupramolecular polymers displaying transformation of mechanical and optical properties on constitutional exchange. Angew. Chem. Int. Ed. 2007, 46, 5007-5010. [CrossRef]

57. Hutchinson, D.J.; Hanton, L.R.; Moratti, S.C. Metal Ion-Controlled Self-Assembly Using Pyrimidine Hydrazone Molecular Strands with Terminal Hydroxymethyl Groups: A Comparison of $\mathrm{Pb}(\mathrm{II})$ and $\mathrm{Zn}$ (II) Complexes. Inorg. Chem. 2011, 50, 7637-7649. [CrossRef]

58. Nosova, E.V.; Chupakhin, A.A.; Lipunova, G.N.; Slepukhin, P.A.; Valova, M.S.; Charushin, V.N. Syntheses, structures, and photophysical properties of $\mathrm{Zn}$-II and Cd-II metal complexes based on benzoylhydrazones. Russ. Chem. B. 2014, 63, 1344-1349. [CrossRef]

59. Wu, D.Y.; Xie, L.X.; Zhang, C.L.; Duan, C.Y.; Zhao, Y.G.; Guo, Z.J. Quinoline-based molecular clips for selective fluorescent detection of $\mathrm{Zn}^{2+}$. Dalton Trans. 2006, 3528-3533. [CrossRef]

60. Kubista, M.; Sjoback, R.; Eriksson, S.; Albinsson, B. Experimental Correction for the Inner-Filter Effect in Fluorescence-Spectra. Analyst 1994, 119, 417-419. [CrossRef]

61. Brouwer, A.M. Standards for photoluminescence quantum yield measurements in solution (IUPAC Technical Report). Pure. Appl. Chem. 2011, 83, 2213-2228. [CrossRef]

62. Caprice, K.; Aster, A.; Cougnon, F.B.L.; Kumpulainen, T. Untying the Photophysics of Quinolinium-Based Molecular Knots and Links. Chem. Eur. J. 2020, 26, 1-13. [CrossRef]

63. Thordarson, P. Determining association constants from titration experiments in supramolecular chemistry. Chem. Soc. Rev. 2011, 40, 5922-5923. [CrossRef] [PubMed]

64. Liu, H.Y.; Dong, Y.S.; Zhang, B.B.; Liu, F.; Tan, C.Y.; Tan, Y.; Jiang, Y.Y. An efficient quinoline-based fluorescence sensor for zinc(II) and its application in live-cell imaging. Sens. Actuators B 2016, 234, 616-624. [CrossRef]

65. Li, N.; Xiang, Y.; Chen, X.T.; Tong, A.J. Salicylaldehyde hydrazones as fluorescent probes for zinc ion in aqueous solution of physiological pH. Talanta 2009, 79, 327-332. [CrossRef]

66. Wu, W.N.; Wu, H.; Wang, Y.; Mao, X.J.; Liu, B.Z.; Zhao, X.L.; Xu, Z.Q.; Fan, Y.C.; Xu, Z.H. A simple hydrazone as a multianalyte $\left(\mathrm{Cu}^{2+}, \mathrm{Al}^{3+}, \mathrm{Zn}^{2+}\right)$ sensor at different $\mathrm{pH}$ values and the resultant $\mathrm{Al}^{3+}$ complex as a sensor for $\mathrm{F}^{-}$. Rsc Adv. 2018, 8, 5640-5646. [CrossRef] 